\title{
Interactions between abusing mothers and their children in two situations
}

\author{
BONNIE K. NASTASI and SUZANNE D. HILL \\ University of New Orleans, New Orleans, Louisiana 70148
}

\begin{abstract}
The interactive patterns between three groups of mother-child pairs were observed in both an unstructured free-play situation and a structured task-oriented situation. There were six mother-child pairs in each group: Group 1 consisted of mothers and their abused children, Group 2, of mothers and their behavior-disordered children, and Group 3, of mothers and children without disorders. The major difference found between the three groups was that abusing mothers did not provide more guidance and direction for their children in the taskoriented situation relative to the free-play situation, whereas the mothers of both control and behavior-disordered children increased their use of these control techniques in the task-oriented situation. The children in all three groups were sensitive to the change of structure and altered their behavior accordingly.
\end{abstract}

Research efforts to isolate the characteristics of abusing parents and their children increased greatly during the 1960 s following publication of work defining the battered child syndrome ( C. Kempe, Silverman, Steele, Brandt, Droegemueller, \& Silver, 1962). Although a few characteristics of the abusing parent have been isolated in this research, abusing parents do not consistently show a common pattern of personality traits (Zigler, 1980). It has been suggested that abusing parents have unrealistic expectations for their children and/or inefficient parenting skills that increase the probability of abuse (Alvy, 1975; Elmer, 1967; Gelles, 1973; Gil, 1970; R. Kempe \& C. Kempe, 1978; Newberger \& Hyde, 1975; Parke \& Collmer, 1975; Smith \& Hanson, 1975; Tracy \& Clark, 1974).

When interaction patterns between abused children and their mothers or peers have been studied, the abused children have appeared similar to insecurely attached infants (Ainsworth, Blehar, Waters, \& Wall, 1978). For example, maltreating mothers were less positive in their interactions with their children than were control mothers as they dropped the children off and picked them up from a day-care center (Lewis \& Schaeffer, 1981). The abused infants interacted less with their mothers and showed less positive play in peer-peer interactions. George and Main (1979) observed that abused children approached the caregivers in a day-care center less often than control children did. They also directed more unprovoked harrassment to their caregivers than did nonabused children. One interpretation of these data is that the abused children, similar to avoidant infants, have a severe approach-avoidance conflict in relation to their mothers (Ainsworth, 1980).

The present work was designed to study further the interactive patterns between abusing mothers and their children. Each mother-child pair was observed in a taskoriented situation that required parental guidance of their children's activities and in a free-play situation similar to that parents experience in a pediatrician's waiting room. We compared the interactions of maltreating mothers with those of mothers of control and behavior-disordered children. The third mother-child pair provided a second group with disordered motherchild relations without the factor of abuse.

\section{METHOD}

\section{Subjects}

Eighteen male children and their mothers participated in the study, six mother-child pairs in each of three groups. The abused group (mean age $=6.94$ years) included children and their mothers who were receiving treatment for abuse in a mental health or crisis center. Four of the children had suffered physical abuse; two had suffered severe neglect. The behavior-disordered group (mean age $=7.24$ years) included children and their mothers who were being treated at a mental health center for management problems. No evidence of abuse was noted for these mother-child pairs. The control group (mean age $=6.90$ years) included children and their mothers who were not in the treatment either for abuse or for management problems. The groups were matched for social class, the parents coming from lower and lower middle-class families. There were no significant differences between the groups for age of the mother or age of the children, for number of children in the family, or for birth order of the child.

The mothers viewed a tape recording of the sessions for a learning experience at a later time. The experimenter and the child's therapist gave positive feedback to the mother, as well as suggestions for dealing with the child's behaviors, while they viewed the tape together.

\section{Procedure}

Each mother-child pair was observed in both a task-oriented and a free-play setting, half in each group receiving the taskoriented setting first and the remainder receiving the free-play setting first. Each session was videotaped for later scoring.

The task-oriented setting provided a structured play situation to the mother-child pairs. The room was furnished with a childsized table and two chairs. Five tasks were arranged on the table: an embedded figures task, a block design task, a vocabulary card, 
a string and beads, and puzzles. The experimenter demonstrated to the mother how to teach each task to her child, asking her to work $3 \mathrm{~min}$ on each task and change tasks when a signal was given. The free-play setting provided an unstructured play situation to the parent-child pair. The room was furnished with a child's table and two chairs, a large chair, a box of toys, and four magazines. The mother was advised that her child could play with the toys. Each parent-child pair was observed for $15 \mathrm{~min}$ in each of these two settings.

The tapes of each session were scored for negative, controlling, and neutral parental behaviors in each of 9010 -sec intervals. We used the system developed by the New Orleans Parent Child Development Center to score parent-child interactions (Andrews, Blumenthal, Bache, \& Wiener, 1976). Parent behaviors of interfering with a child's activities, restraining the child, criticizing the child, and ignoring the child's attempt to interact were scored as negative behaviors. Parental behaviors that directed the child's behavior or instructed the child were scored as control behaviors. Focus of attention away from the child and passive observation of the child were scored as neutral behaviors. The child's interactive behaviors of cooperation with parental requests and initiation of contact with the parent were also scored. Each behavior was scored if it occurred in a 10 -sec interval, the score range for each behavior being 1 to 90 . A second trained observer scored half of the tapes. If a disagreement in scoring occurred, the two raters rescored the tape together.

\section{RESULTS}

The mother's use of control techniques varied as a function of subject group $[F(2,25)=6.76, p<.01]$. Mothers of behavior-disordered children used significantly more directions and instructions $(p<.05)$ in the unstructured situation (Newman-Keuls test) than did control and abusing mothers. Mothers of both control and behavior-disordered children significantly increased their controlling techniques $(p<.05)$ in the structured situation, but the mothers of abused children did not (Newman-Keuls test) (see Figure 1). The mothers did not differ in the amount of negative or neutral interactions with their children in these two settings.

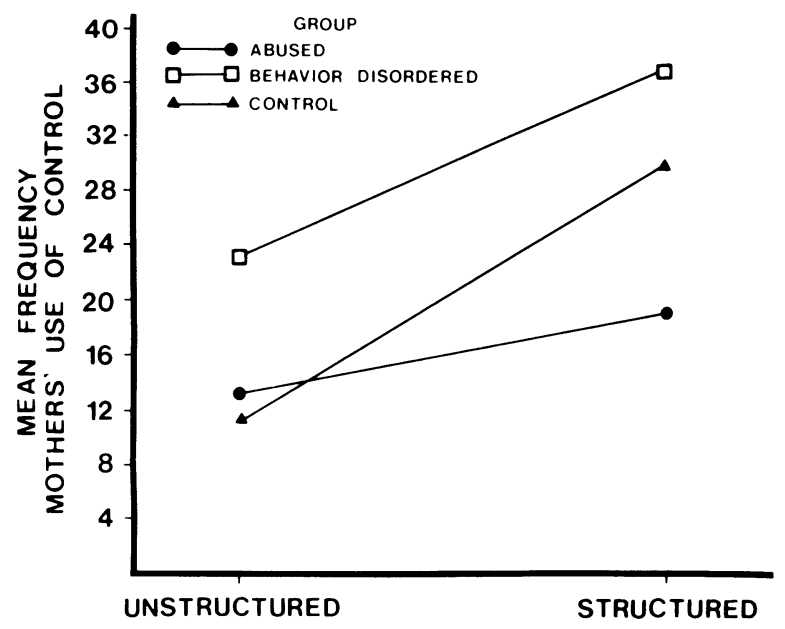

Figure 1. The mean frequency with which mothers of abused, behavior-disordered, and control children directed and instructed their children in structured and unstructured settings.
Both parents' and children's interactive behavior varied as a function of the amount of structure in the situation. The parents initiated more contact with their children in the structured setting, whereas the children initiated more contact with their parents in the unstructured situation $[F(1,17)=62.91$ and 13.18 , respectively; $\mathrm{p}<.01]$, but there were no significant group differences. Similarly, the children did not differ among themselves in the amount of cooperation with their parents, but all groups cooperated more in the structured situation. Cooperation ranged from $51 \%$ to $54 \%$ of intervals in the unstructured situation and from $76 \%$ to $94 \%$ in the structured situation.

\section{DISCUSSION}

The parents observed in these two contrived settings, one resembling a waiting room situation and the other a teaching situation, reacted in remarkably similar ways. The major difference between them was that the abusing parents did not provide more guidance and direction for their children in the teaching situation in comparison with the free-play situation, whereas the parents of both control and behavior-disordered children did use more of these controlling techniques in the structured teaching situation. Moreover, mothers of behavior-disordered children were more controlling in both situations then were maltreating and control mothers. There has recently been much interest in the types of social interactions in problem solving situations that influence cognitive development (Wertsch, 1978). It has been suggested that the regulation parents provide in a problem solving situation affects their children's development of selfregulation in problem solving. The finding that abusing mothers did not increase their regulation of their children's behavior in the teaching situation suggests that one outcome of abuse for the children may be a delay in the development of self-regulation in problem solving (metacognition).

The abusing parents in this study did not display more negative behaviors toward their children than did the other parents observed. This finding suggests that abusing parents' negative reactions to their children are not constant factors in their interactions but may occur when elicited by unfavorable or stressful conditions. They were observed, however, in a setting in which they were receiving treatment and may have considered that their behavior was being monitored in relation to the treatment they received.

The children in this study were similar to each other in their reaction to these situations regardless of parent group. The abused children, like the children in the other two groups, were sensitive to the change in the structure of the situation and altered their behavior accordingly. It is possible that when treatment is directed to the parent-child pair as a unit, the child's relatively normal reaction to structure will be an asset in behavior change in the parent.

\section{REFERENCES}

Ainsworth, M. D. S. Attachment and child abuse. In G. Berbner, C. J. Ross, \& E. Zigler (Eds.), Child abuse: An agenda for action. New York: Oxford University Press, 1980.

Ainsworth, M. D. S., Blehar, N. C., Waters, E., \& Wall, S. Patterns of attachment: A psychological study of the strange situation. Hillsdale, N.J: Erlbaum, 1978.

Alvy, K. T. Preventing child abuse. American Psychologist, 1975, 30, 923-928.

Andrews, S. R., Blumenthal, J. B., Bache, W. L. III, \& Weiner, G. Fifth year report. New Orleans: New Orleans Parent Child Development Center, 1976. 
Elmer, E. Children in jeopardy. Pittsburgh: University of Pittsburgh Press, 1967.

Gelles, R. J. Child abuse as psychopathology: A sociological critique and reformulation. American Journal of Orthopsychiatry, 1973, 43, 611-621.

George, C. E., \& MAIN, M. Social interactions of young abused children: Approach, avoidance, and aggression. Child Development, 1979, 50, 306-318.

GIL, D. G. Violence against children: Physical abuse in the United States. Cambridge, Mass: Harvard University Press, 1970.

Kempe, C. H., Silverman, F. N., Steele, B. F., Brandt, F., Droegemueller, W., \& Silver, H. K. The battered-child syndrome. Journal of the American Medical Association, 1962, 181, 105-112.

Kempe, R. S., \& Kempe, C. H. Child abuse. Cambridge, Mass: Harvard University Press, 1978.

Lewis, M., \& Schaeffer, S. Peer behavior and mother-infant interaction in maltreated children. In $M$. Lewis \& L. A. Rosenblum (Eds.), The uncommon child: Genesis of behavior (Vol. 2). New York: Plenum, 1981.
Newberger, E. H., \& Hyde, J. N. Child abuse: Principles and implications of current pediatric practice. Pediatric Clinics of North America, 1975, 22, 695-715.

Parke, R. D., \& Collmer, C. W. Child abuse: An interdisciplinary analysis. In M. E. Hetherington (Ed.), Child development research (Vol. 5). Chicago: University of Chicago, 1975.

Sмiтh, M., \& Hanson, R. Interpersonal relationships and childrearing practices in 214 parents of battered children. British Journal of Psychiatry, 1975, 127, 513-525.

TraCY, J., \& ClaRK, E. H. Treatment for child abusers. Social Work, 1974, 19, 338-342.

Wertsch, J. V. Adult-child interaction and the roots of metacognition. Quarterly Newsletter of the Institute for Comparative Human Development, 1978, pp. 15-18.

Zigler, E. Controlling child abuse: Do we have the knowledge and/or the will? In G. Berbner, C. J. Ross, \& E. Zigler (Eds.), Child abuse: An agenda for action. New York: Oxford University Press, 1980.

(Received for publication May 13, 1982.) 